\title{
A review of research into stakeholder perspectives on inclusion of students with autism in mainstream schools
}

\author{
Jacqueline Roberts and Kate Simpson
}

Autism Centre of Excellence, School of Education and Professional Studies, Griffith University, 176 Messines Ridge Rd, Mt Gravatt 4122, Australia

\section{ABSTRACT}

Increasing numbers of students with autism are being educated in mainstream schools. However, outcomes for students with autism are poor when compared to typical students and students with other developmental disabilities. In order to better understand facilitators and barriers to success at school for students with autism, research into the attitudes of key stakeholders, educators, parents, people with autism, to inclusion in mainstream schools for students with autism, was reviewed. Key themes emerging included attitudes to inclusion, the characteristics of autism and social communication in particular and interaction with the school environment, and consequent student problem behaviour. Level of knowledge and understanding of school staff emerged as the primary issue with all stakeholders identifying the need for more training. Other support needs identified included the need for structural support, resources and funding. Parents, in particular, identified the need for a collaborative approach to the education process. The findings highlight the need to translate theory into practice to increase capacity in schools to provide effective educational programmes for students with autism.
ARTICLE HISTORY

Received 21 October 2015

Accepted 16 January 2016

KEYWORDS

Inclusion; stakeholder perspectives; autism spectrum disorder; schools

\section{Introduction}

Autism is a neurodevelopmental condition that affects social communication in particular. People with autism also have difficulties with restricted or repetitive behaviours and for many this includes sensory problems (American Psychiatric Association 2013). Autism makes it difficult to make sense of the world, disables conventional insight and results in difficulty understanding and communicating about internal and external states and behaviour (self and others). The way these characteristics manifest and impact on the person with autism and those around them in both the short and long term depends on the social and environmental context (Prizant 2015). The term autism is used to refer to all individuals on the autism spectrum.

Since the mid-90s, UNESCO's Salamanca Statement (United Nations Educational Scientific and Cultural Organisation 1994) commitment to inclusive education has increased for all regardless of disability resulting in a steady rise in the relative numbers of students in mainstream schools identified with a disability (Snyder and Dillow 2013). Inclusion involves 'the incorporation of all children and youths as active fully participating members of the school community' (Lynch and Irvine 2009, 286). Adherence to a rights-based perspective is associated with increasing numbers of students with disabilities, including autism, in mainstream classrooms. In the USA, there were $31.7 \%$ students with disabilities in mainstream classes in 1989 and 56.8\% in 2007 (Snyder and Dillow 2013), while in 
another study $86.3 \%$ of principals $(n=51)$ reported students with autism received inclusive education in their school (Loiacono and Palumbo 2011).

While most educators support a rights-based approach to inclusion in principle and advocate the education of all in mainstream classrooms and the avoidance of labelling, there are tensions among educators, in particular in relation to the provision of autism-specific adaptations or autism-specific staff training. This is considered to be potentially exclusionary by rights-based inclusionists. In contrast, there are those who take a needs-based perspective who are more likely to advocate for students with autism to be identified and for staff to have autism-specific training. Educators with a needsbased perspective are also likely to advocate for the provision of a range of autism-specific educational placements including segregated provision for some (Ravet 2011).

In addition when children with autism are enrolled in mainstream classrooms, educators and parents are concerned with significant numbers of cases where this is not working for either students with autism or the school and where exclusion of the student is the outcome (House of Commons Education and Skills Committee 2006). Unfortunately educational outcomes for students with autism at school (Ashburner, Ziviani, and Rodger 2010) and once they leave school (Australian Bureau of Statistics 2012; Howlin et al. 2014) are poor, compared to both the typical population and other disability groups.

Examination of research into stakeholder perspectives of autism and education suggests that while policies are in place (and in some countries mandated) to support the inclusion of students with disabilities in mainstream education, policies are not necessarily being translated to practice. This appears to be particularly the case for autism. In addition there is a case to suggest that students with autism in mainstream education benefit from both general and specialist autism disability policy and good practice.

In this paper we examine research into the perspectives of stakeholders of the education of students with autism (teachers, parents and students), in order to understand their perception of the extent to which schools are inclusive and their perception of the effect of the current system of education provision on practice in schools and outcomes for students. Stakeholders are viewed as providing valuable insight into the way education policy translates to practice and factors that either promote or are barriers to successful inclusion.

The goal is to construct an understanding of stakeholder perspectives on how inclusive practices for students with autism are applied to practice, perceived facilitators and barriers and implications for success at school.

\section{Method}

A comprehensive search was conducted using the databases, PsycINFO, ERIC, ProQuest Educational Journals, for the period 2004-July 2015. Combinations of the search terms - autis*, inclusion, inclusive, education, school/s, parent/s, teacher ${ }^{\star}$, student/s, children, mother, father and Asperger ${ }^{*}$ - were used. Reference lists of the selected articles were hand searched to identify other relevant studies.

Articles were included for analysis if they met the following criteria:

(1) Published in a peer-reviewed journal

(2) Investigated the perspectives of students with autism, peers, parents, school staff and professional support staff working in education,

(3) Focused on primary and secondary mainstream education contexts

Studies were excluded if they were focused on transition periods (commencing school, primary to secondary and secondary to post-school). A further analysis excluded studies focused on early intervention, special education schools or autism-specific schools, and studies where information from these settings could not be clearly separated from information from mainstream schools. The review 
did not include studies of outcome-based measures, and comparative studies with other disabilities and/or typically developing peers.

\section{Data analysis}

Analysis was conducted on the results and findings section of the included articles. A provisional code list was generated using the headings identified in the articles (Miles and Huberman 1994). Subsequent readings of the articles were conducted and codes were revised, with the authors looking for similarities and differences between the codes. The codes were then revised to ensure that they were representatives of the data and to reduce code overlap. The authors underwent a process of grouping the codes under key descriptive themes in order to construct an understanding of stakeholders' perspective on inclusive practice for students with autism.

\section{Results}

Twenty-three studies were identified that met the selection criteria. These were categorised according to participant characteristics, context, country and method (see Table 1). The studies included the perspectives of 75 students with autism (4 primary, 41 secondary), and 30 adults providing retrospective data on their school experience; 347 parents of students with autism and 749 education professionals including principals, special education teachers, general teachers, teacher assistants, school psychologists, specialists and school district officers. The studies were conducted in the USA (9) and the UK (7), Australia (3), Canada (2), Turkey (1) and India (1). Studies reported in Table 1 include nine from primary, six from secondary, seven across primary and secondary, and one not specified. Semi-structured interviews were the predominant method of data collection, used in 10 studies. Four studies included quantitative data analysis (Humphrey and Symes 2013; Loiacono and Palumbo 2011; Segall and Campbell 2012, Whitaker 2007).

Five key themes that emerged from the data focused on factors identified by stakeholders as having an impact on the effectiveness of inclusive practice for students with autism. These included attitudes to inclusion, knowledge and understanding of autism, social communication behaviours, perceived challenging behaviours and support networks.

\section{Attitudes to inclusion}

Education professionals, in both the UK and USA, and parents surveyed in the UK generally held positive attitudes about the inclusion of students with autism (Humphrey and Symes 2013; Segall and Campbell 2012; Whitaker 2007). Perception of inclusive practice was associated with the participant's view and understanding of inclusion compared to integration, that is, the process of including a child with autism focusing on adaption of the learning environment to meet the child's needs (inclusion) in contrast to integration when the child is expected to adapt to the environment. Humphrey and Symes (2013) reported a more moderate view of integration correlated with higher levels of perceived inclusion. Both education professionals and parents considered that school commitment and willingness to accept students were associated with inclusion (Waddington and Reed 2006).

\section{Perceived benefits of inclusion}

According to parents and education professionals, inclusive practice benefited students with autism, their peers and teachers (Humphrey and Symes 2013; Sansosti and Sansosti 2012; Waddington and Reed 2006; Yumak and Akgul 2010). Benefits included promoting awareness and acceptance of diversity, reducing stigma, and providing an opportunity for students with autism and their peers to experience new social situations and develop social skills (Humphrey and Symes 2013; Sansosti and Sansosti 2012; Waddington and Reed 2006). According to education professionals, inclusion 
Table 1. Included studies.

Citation
Bilken and B
Coffey and O
(2004)
Conn (2014)

Emam and Farrell (2009)

Gray and Donnelly

(2013)

Hay and Winn (2005)

Hedges et al. (2014)

Saggers, Hwang, and Mercer (2011)

Sansosti and Sansosti (2012)

Jackson Brewin, Renwick, and Schormans (2008) Johansson (2014)

Lindsay et al. (2013)

Loiacono and Palumbo

(2011)

Mayton (2004)

Sciutto et al. (2012)

\section{Class teacher Support worker Mother}

Participant characteristics

Student with ASD (adolescent) Mother and father (two children with ASD aged 11 and 14 years) Student with ASD (9 years)

Students with ASD (indirect), 7-16 years $(n=17)$ Teachers

Teacher aides

Special educational need co-ordinators Students with ASD, $7-8$ years $(n=2)$,

Mothers $(n=2)$

Parents $(n=17)$

Special education teachers $(n=7)$

Teachers $(n=89)$

Students with ASD $(n=9)$

Individuals with ASD - current and post-secondary school students $(n=5)$ Parents $(n=10)$

Special education personnel $(n=21)$ General education teachers $(n=5)$

Students with AS/HFA $(n=20)$

$$
\text { 5) }
$$

SENCO $(n=10)$

Secondary

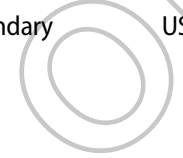

USA

Northern Discussion

reland/UK

Australia

Focus group

Interviews with students with ASD

A Focus groups
UK

UK

USA

Focus groups

Key informant interviews Open meeting student diaries and drawings Questionnaire
Semi-structured interviews nce sessions Semi-structured interviews

UK Observations
Senior management $(n=11)$

Class teachers $(n=32)$

Parents $(n=35)$

Paraprofessionals $(n=29)$

Classroom teacher $(n=44)$

Related service provider $(n=5)$

Education administrator $(n=11)$

Parents $(n=9)$

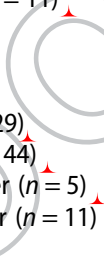

Principals $(n=13)$

Class teachers $(n=11)$

Special educators $(n=8)$

Counsellors $(n=3)$

Parents $(n=18)$

Private specialists $(n=11)$

Educators $(n=13)$

Principals $(n=51)$

Student with ASD, 10 years $(n=1) \quad$ Primary

Secondary

Primary Primary
(private)

Primary)

Primary

Secondary

Secondary

Primary

Educators $(n=15)$

Principal

Assistant principal

Behaviour specialist

School psychologist

Teacher $(n=3)$

Special education teacher $(n=8)$

Parents of students with AS, aged 6-18 Primary

years $(n=59)$

Adults with $\mathrm{AS}(n=27)$

Unspecified $(n=8)$
Canada Semi-structured interviews

USA Questionnaire

USA Structured interview Observations IEP and work samples

Australia Interview

USA Focus groups 
Table 1. Continued.

\begin{tabular}{|c|c|c|c|c|}
\hline Citation & Participant characteristics & Context & Country & Measure \\
\hline $\begin{array}{l}\text { Segall and Campbell } \\
\text { (2012) }\end{array}$ & $\begin{array}{l}\text { Education professionals }(n=196) \\
\text { Administrators - } 39 \\
\text { General education teachers }-53 \\
\text { Special education }-71 \\
\text { School psychologists }-33\end{array}$ & $\begin{array}{l}\text { Primary } \\
\text { Secondary }\end{array}$ & USA & $\begin{array}{l}\text { Autism Inclusion } \\
\text { Questionnaire (stats) }\end{array}$ \\
\hline $\begin{array}{l}\text { Soto-Chodiman, Pooley, } \\
\text { and Taylor (2012) }\end{array}$ & Teachers $(n=12)$ & Primary & Australia & Semi-structured interview \\
\hline $\begin{array}{l}\text { Waddington and Reed } \\
\text { (2006) }\end{array}$ & $\begin{array}{l}\text { Parents }(n=23) \\
\text { Local authority workers }(n=25)\end{array}$ & Not specified & UK/England & Focus groups \\
\hline Whitaker (2007) & Parents $(n=172)$ & $\begin{array}{l}\text { Primary } \\
\text { Secondary }\end{array}$ & UK & $\begin{array}{l}\text { Questionnaire (rating items } \\
\text { and open-ended questions) }\end{array}$ \\
\hline Yumak and Akgul (2010) & $\begin{array}{l}\text { Education professionals }(n=117) \\
\text { School teachers and administrators }\end{array}$ & Primary & Turkey & Questionnaire \\
\hline
\end{tabular}

provided students with autism the opportunity to engage in more academic tasks, and the use of class-wide strategies to address behaviour and social issues which benefitted all students (Sansosti and Sansosti 2012). Parents viewed inclusion as providing their child with a better chance of a 'normal' life (Waddington and Reed 2006).

\section{Attitude to and effect of disclosure of diagnosis: issue of labelling}

Knowledge of the diagnosis potentially resulted in preconceived ideas and expectations of 'autistic' behaviour. Conversely lack of awareness of autistic characteristics resulted in misunderstanding of behaviour and overly high expectations of the student (Jackson Brewin, Renwick, and Schormans 2008). Parents' choice of not to have their child formally diagnosed created issues for educators, such as ineligibility for resources, and made managing concerns from other parents more challenging. Educators' perceived lack of disclosure made creating an atmosphere of peer acceptance and promoting peer understanding more difficult and increased the risk of students with autism being excluded (Lindsay et al. 2013). At least one student preferred others not to know about his autism as he did not want to be treated differently (Humphrey and Lewis 2008).

\section{Knowledge and understanding of autism}

Education professionals' knowledge and understanding of autism and their awareness and use of effective strategies were identified by students, parents and education professionals as key factors impacting on the success or otherwise of inclusive practice (Hay and Winn 2005; Hedges et al. 2014; Humphrey and Lewis 2008; Humphrey and Symes 2013; Iadarola et al. 2015; Jackson Brewin, Renwick, and Schormans 2008; Lindsay et al. 2013; Mayton 2004; Sansosti and Sansosti 2012; Sciutto et al. 2012; Segall and Campbell 2012; Soto-Chodiman, Pooley, and Taylor 2012; Waddington and Reed 2006; Whitaker 2007; Yumak and Akgul 2010). Perceived level of knowledge and understanding of autism varied. Principals, special education teachers and school psychologists rated themselves as more aware of strategies than general education teachers (Humphrey and Symes 2013; Segall and Campbell 2012). Loiacono and Palumbo (2011) reported that $62.7 \%$ of principals surveyed were confident they were pedagogically prepared to evaluate and support teachers of students with autism. However, the majority of the general education teachers expressed concern about their limited knowledge of autism and relevant teaching strategies (Lindsay et al. 2013; Soto-Chodiman, Pooley, and Taylor 2012; Yumak and Akgul 2010). In particular, general education teachers felt their limited knowledge resulted in the use of reactive rather than proactive approaches (Lindsay et al. 2013). Lack of training for paraprofessionals was also highlighted (Iadarola et al. 2015).

Parents expressed frustration at the narrow focus of education professionals on academic, as opposed to social, outcomes at school (Whitaker 2007), their lack of understanding of autism, the 
lack of resources and training for professionals and paraprofessionals and the negative impact of uninformed teacher behaviour on students with autism (Iadarola et al. 2015). Similarly, students with autism believed that education professionals required greater understanding of autism and factors impacting on their participation at school. These included stress and anxiety caused by environmental factors such as noise, crowding, limited mobility opportunities, curriculum demands and changes in routine (Gray and Donnelly 2013; Humphrey and Lewis 2008; Mayton 2004; Saggers, Hwang, and Mercer 2011; Sciutto et al. 2012). Teacher flexibility was viewed by both students (Saggers, Hwang, and Mercer 2011; Sciutto et al. 2012) and parents (Coffey and Obringer 2004) as a desirable trait to support inclusive practices.

\section{Powerful interests and motivation}

The idea of utilising students' special interests to facilitate social interactions produced mixed responses. On one hand, students with autism were viewed positively by peers as experts' in the area, while on the other hand peers viewed it as unusual for someone to have such a strong focus on a specific interest area (Conn 2014; Humphrey and Lewis 2008).

\section{Social communication behaviours}

The social communication characteristics of students with autism were perceived as having a significant impact on the teacher-student and student-peer/relationship in primary (Gray and Donnelly 2013) and secondary schools (Hedges et al. 2014; Saggers, Hwang, and Mercer 2011). Teachers found the need to ensure instructions and class communications were clear and unambiguous inhibited typical teacher-student interaction (Emam and Farrell 2009; Hay and Winn 2005; Soto-Chodiman, Pooley, and Taylor 2012). Adapting mode of communication was viewed as time-consuming and led to frustration and resentment for some teachers (Emam and Farrell 2009). Teachers commented on increased demands arising from the difficulties students experienced in generalising social behaviours across activities and the need to teach these behaviours in relation to each activity (Emam and Farrell 2009).

The necessary use of Augmentative and Alternative Communication (AAC) systems in school to support communication resulted in challenges for the student with Autism (Bilken and Burke 2007). From the student's perspective, communicating using an AAC system required concentration, time to indicate a desire to talk, acknowledgement he would like to talk and then time provided for him to talk. The lack of these considerations resulted in the student missing communication opportunities (Bilken and Burke 2007).

\section{Student-peer relationships}

The attitude of students with autism towards socialising with peers was mixed; some preferred to spend time by themselves, others enjoyed socialising as long as it was in the context of a conversation of interest to them, while others found coping with 'normal' social and academic daily situations stressful (Saggers, Hwang, and Mercer 2011; Sciutto et al. 2012). Typical peers were willing to assist students with autism and support communication with them in class but this was less evident during recess. Teachers felt that they were required to facilitate interaction between students with autism and their peers (Mayton 2004; Soto-Chodiman, Pooley, and Taylor 2012). The tendency for students with autism to behave differently from their peers and their difficulties or lack of skills in responding to social situations resulted in students with autism experiencing isolation, teasing and bullying, which were perceived by students, parents and education professionals to be frequently encountered by students with autism (Gray and Donnelly 2013; Hay and Winn 2005; Hedges et al. 2014; Humphrey and Lewis 2008; Humphrey and Symes 2011; Johansson 2014; Mayton 2004; Saggers, Hwang, and Mercer 2011; Sciutto et al. 2012). 


\section{Perceived challenging behaviours}

The behaviour of students with autism was viewed by some educators as inappropriate in the school context, and disruptive in the classroom (Johansson 2014). Four studies investigated the types of behaviours displayed by students with autism and the implications of these behaviours for inclusion (Hay and Winn 2005; Humphrey and Symes 2013; Sansosti and Sansosti 2012; Soto-Chodiman, Pooley, and Taylor 2012). Educators identified stereotypic utterances, physical mobility during quiet periods, off-task behaviour and task refusal as distracting and disruptive behaviours (Hay and Winn 2005; Sansosti and Sansosti 2012; Soto-Chodiman, Pooley, and Taylor 2012). Behaviours that were identified as unacceptable and potentially impacting on inclusion were self-injury, severe tantrums and physical aggression towards peers (Sansosti and Sansosti 2012), while displaying emotions inappropriately was rated by education professionals as the most difficult behaviour to manage (Humphrey and Symes 2013). The responsibility of managing the behaviour was frequently given to special education staff and there was a lack of consensus in schools on management procedures (Hay and Winn 2005). Management procedures were implemented with more consistency when there was collaboration with parents on behaviour management approaches (Soto-Chodiman, Pooley, and Taylor 2012).

Education professionals expressed concern about the impact of challenging behaviour on academic achievement and the safety of other students (Sansosti and Sansosti 2012). They also found it difficult to explain to peers (Lindsay et al. 2013), and perceived peers as experiencing frustration and having difficulty understanding why the pupil with autism was treated differently. Peers were uncomfortable when faced with inappropriate or aggressive behaviour (Humphrey and Symes 2013). Education professionals, parents and students with autism perceived educators' lack or limited knowledge of autism limited their understanding of students' behavioural differences, the impact characteristics of autism could have on behaviour, and strategies and approaches to managing behaviour (Hay and Winn 2005; Johansson 2014; Lindsay et al. 2013; Sciutto et al. 2012; Whitaker 2007).

\section{Support networks}

The availability of resources and personnel support was viewed by educators and parents as the most significant factor in relation to the capacity of schools to meet inclusion needs. Lack of funding was viewed by parents (Waddington and Reed 2006) and educators (Lindsay et al. 2013) as the main reason for the failure of inclusion.

\section{Structural support in educational institutions}

Perceived barriers included lack of funding for education assistants, lack of appropriate resources and equipment particularly for students with AS or HFA, lack of time to provide additional help to children with autism, particularly in older grades (Lindsay et al. 2013), lack of continuity of services, inconsistencies in the use of strategies across the school day, inconsistencies between school and home expectations (Hedges et al. 2014; Jackson Brewin, Renwick, and Schormans 2008) and lack of autism-specific services (Soto-Chodiman, Pooley, and Taylor 2012). Special education teachers were concerned about the limited provision of facilities to support students with autism, for example, reduced noise environments (Hay and Winn 2005).

\section{Support for education professionals}

Education professionals believed that general education teachers require more collegial support to include students with autism compared to other students with disabilities (Sansosti and Sansosti 2012). Limited knowledge and difficulty in addressing individual student needs were perceived as challenging and stressful for teachers (Emam and Farrell 2009; Soto-Chodiman, Pooley, and Taylor 2012; Yumak and Akgul 2010). Support for teachers was provided by school psychologists 
(Soto-Chodiman, Pooley, and Taylor 2012), principals and/or special educators (Loiacono and Palumbo 2011).

School management and subject teachers believed that they lacked continuing professional development opportunities and felt they would benefit from further training (Humphrey and Symes 2013). It was suggested systems-wide initiatives supporting autism inclusion and in-service training about autism and inclusive practices would contribute to success (Sansosti and Sansosti 2012), as would additional time to implement best practices (Hedges et al. 2014). While some teachers believed that the additional work generated by having students with autism in their class warranted additional pay (Yumak and Akgul 2010).

\section{Support for students with autism}

Education professionals believed that students with autism require more support than other students with disabilities and the support required was unique to autism (Sansosti and Sansosti 2012). There is, however, a lack of clarity as to who is responsible for providing this support (Hedges et al. 2014). Students with autism and teachers viewed support personnel (special education teachers, special education assistants and most commonly teacher assistants) as providers of support for academic and personal tasks, social situations and managing behaviour (Emam and Farrell 2009; Hay and Winn 2005; Saggers, Hwang, and Mercer 2011; Sansosti and Sansosti 2012; Soto-Chodiman, Pooley, and Taylor 2012). Teachers' preference for teacher assistant support was associated with positive attitudes towards inclusion (Emam and Farrell 2009).Primary and secondary teachers relied on teacher assistants to ensure student's academic tasks were completed, and to manage behaviour (Emam and Farrell 2009; Sansosti and Sansosti 2012), success was influenced by the teacher's knowledge of how to incorporate assistants effectively within the classroom (Hay and Winn 2005). In secondary schools teacher assistants were viewed as the knowledgeable person about the student with autism (Emam and Farrell 2009) influenced by the teacher assistant's level of knowledge and training working with students with autism (Soto-Chodiman, Pooley, and Taylor 2012). The use of teacher assistants was also viewed as a potential barrier to inclusion when students with autism relied on teacher assistant support rather than support from teacher and peers (Emam and Farrell 2009; Sansosti and Sansosti 2012). Furthermore, students with autism while appreciating the support desired it to be unobtrusive to avoid being identified as different (Emam and Farrell 2009; Hay and Winn 2005; Humphrey and Lewis 2008; Saggers, Hwang, and Mercer 2011).

\section{Home-school relationship}

Education professionals and parents alike viewed good communication with parents as an essential component of effective inclusion (Waddington and Reed 2006). There was some difference in perception of service delivery between education professionals and parents; parents believed they received little help or information, while education professionals believed they supported parents across the school years (Waddington and Reed 2006). Whitaker (2007) reported 60\% of parents were satisfied with the home-school relationship. While Hay and Winn (2005) found that parents believed more support was required for families coping with their child at home and that homeschool communication could be improved.

\section{Discussion}

Attitudes to inclusion reflected in the research among stakeholders were generally mixed. Educators who were committed to integration were generally positive, particularly when they had had previous successful experience enrolling students with disability. Benefits were noted by both educators and parents for students with autism and their peers in relation to gains in attitude to diversity and academic and social skill development. However, education professionals perceived peers as experiencing frustration and difficulty understanding why the student with autism was treated differently. It is interesting to speculate whether this would be the case if autism was a more visible (e.g. physical) 
disability. Parents and educators spoke of positive and negative outcomes in terms of attitude of others towards students identified with autism suggesting knowledge of the diagnosis resulted in 'autistic expectations' of children while lack of knowledge resulted in misunderstanding of 'autistic' behaviours and increased the risk of exclusion. However, educators felt strongly that labelling resulted in access to resources. While most parents believed that inclusion gave their children a better chance to have a 'normal life', only a slight majority expressed satisfaction with the inclusion of their child suggesting that many believed mainstream placement was not working for their child. There was a significant gap in the research in relation to the views of people with autism, and as a result we know very little about their perspective of the issue. It appears that we have come a long way since the time when children with autism were considered to be 'ineducatable' (Wolff 2004) or at best belonged only in special schools, to general acceptance of the right for children to be educated in mainstream schools; however, the practical challenges associated with inclusion of children with autism continue to present barriers.

Knowledge and understanding of autism was nominated as a key factor in successful inclusion of student with autism in mainstream education by all stakeholders including those with autism. Interestingly, only a slight majority of principals believed they had the knowledge and experience to support staff in their schools in relation to the inclusion of students with autism, which is a major concern because principals play the key role in determining the climate and culture of the school. The importance of training for education staff was highlighted and seen as lacking by most. When teachers are not trained in the use of the autism lens, learners fail to meet their potential and will experience isolation, frustration, crisis and exclusion, while their teachers experience frustration and stress (Batten and Daly 2006; Ravet 2011). Widespread mainstream educator training in autism would mean that other students in mainstream classrooms could benefit from the principles and strategies associated with good autism practice (Howley and Kime 2003). An integrative approach' (Ravet 2011) is to prioritise training in autism for all staff in mainstream schools, to ensure that all learning environments and pedagogies are suitably adapted to enable learners on the autism spectrum to participate and succeed in and out of the classroom.

The frequency and intensity of behaviours that challenge are positively correlated to autism symptom severity (Matson, Wilkins, and Macken 2008) and level of intellectual disability (McTiernan et al. 2011). Teachers frequently described the behaviour of students with autism as inappropriate and disruptive at school. Severe internalising and externalising behaviours such as self-injury and aggression towards others potentially resulted in exclusion for the student. Teachers were also concerned about the effect of these behaviours on other students in the school and potential disruption. However, behaviour does not occur in a vacuum. Most of the behaviours of concern described by teachers were not primary characteristics of autism, rather the result of interaction between student characteristics and the school environment. There is a lack of research into the perspectives of students with autism on behaviour at school and as a result poor understanding of which aspects of the school environment are particularly challenging. Educators' lack of knowledge about autism, and the interaction of student characteristics and the environment in particular, coupled with their concerns about the disruptive effect of student problem behaviour, emerge as major issues and likely cause of exclusion for the student with autism.

Social communication characteristics of autism and relationships emerge as a key mediator of success school. All aspects of school life from learning in class to relating to peers in the playground were perceived by stakeholders to be negatively impacted by student communication limitations. The necessary adaptions (e.g. AAC) were seen as limited in effectiveness and time-consuming while verbal students with autism were noted to have difficulty relating to teachers and peers. Students with autism reported finding social interaction particularly stressful and did not appear highly motivated to socialise with others while parents believed that their children wanted to belong but were rejected by their peers because of their social difficulties. Peers were reported to be prepared to assist students with autism to communicate to a limited degree; however, this tended to be limited to the classroom. There was some interest reported in the research in the use of powerful interests to 
engage and motivate students with autism and to facilitate interaction with peers; however, this was also perceived as unusual and odd.

Bullying and teasing were seen as major concerns for students with autism, despite support from peers at times. Bullying is a major factor in the high rates of anxiety and other comorbid disorders reported in the autism population (Hebron and Humphrey 2014).

Lack of necessary supports in school at an individual, class and school level was identified by stakeholders as the primary reason for school failure. Support identified as necessary at a school level included reduced class sizes, increased teacher time, availability of support personnel such as teacher aides and expert consultants/mentors for staff, all of which potentially benefit a whole range of diverse learners including students with autism in the school. Environmental supports such as facilities for students with autism such as sanctuary spaces, sound reduction in classrooms, personnel to ensure continuity of services, support for post-school transition and the capacity to adjust and modify student assessment tasks were all highlighted. Both students with autism and school staff identified the provision of support personnel to assist students to manage in and out of the classroom as high priority; however, students with autism wished for such support to be unobtrusive and teacher aides were also viewed as potential barriers to inclusion. Education and training in inclusion and autism was highly prioritised by school leaders and staff themselves suggesting that this should be a priority, if not mandatory, in school systems. A view supported by parents who were frustrated by lack of staff expertise, particularly in relation to their child's social participation at school. Parents generally felt unsupported by school staff and many felt the home-school relationship could be improved, while school staff typically viewed themselves as supportive of parents. A clear contrast emerged here in relation to perception of support suggesting the need for more research in this area.

In summary, examination of the results of this review of recent research literature into stakeholder attitudes to inclusion of students with autism in mainstream schools suggests that while there is a general philosophical commitment to the inclusion of students with autism in mainstream schools in line with a rights-based approach to education of children with disabilities, there are significant barriers in practice which are not being adequately addressed. This in turn has a direct negative impact on the school experience for students on the autism spectrum, results in poor educational outcomes and significant stress and strain for schools. We know what needs to be done but until research is more effectively translated to practice, outcomes for students with autism and for schools will not improve.

\section{Limitations of the paper}

The discussion is limited to the perspectives of stakeholders in the autism community reflected in the research literature. There is a lack of systematic investigation into perspectives and issues for students with autism themselves and as a result limitations in relation to the representativeness of the perspectives reflected. In addition the paper does not address issues for stakeholders involved in non-mainstream schools. This group is likely to include those with the least ability to communicate and severe autism and/or significant intellectual disability. Segregated schooling may have been a choice or the result of failure in mainstream settings. The perspectives of this group are an important topic for future research.

\section{Conclusion}

Increasing numbers of students with autism enrolled in mainstream schools mean it is highly likely that teachers will have one or more students with autism in their classes each year. Autism is no longer a rare condition or only the preserve of special education, students with autism are increasingly the business of regular schools, yet what little we know of educational outcomes for these students to date suggests that students with autism are not doing as well as we would expect given their evident cognitive abilities, or compared to other students with and without disabilities. Post-school 
outcomes for students with autism are generally the poorest of all students while parents report high levels of suspension and exclusion.

While the majority of stakeholders agree with the principles of inclusion for all students with disability in mainstream education, it appears that current practice is not meeting the needs of students with autism and schools. The research describes what works for students with autism and for schools. This review highlights the need for more work to be done to translate theory into practice and build capacity in education systems to enable the participation of students with autism in mainstream schools.

\section{Funding}

The authors acknowledge partial funding support for the research from The Griffith Institute of Educational Research.

\section{Notes on Contributor}

\section{References}

American Psychiatric Association. 2013. Diagnostic and Statistical Manual (DSM-5). 5th ed. Arlington, VA: American Psychiatric Publishing.

Ashburner, J., J. Ziviani, and S. Rodger. 2010. "Surviving in the Mainstream: Capacity of Children with Autism Spectrum Disorders to Perform Academically and Regulate Their Emotions and Behavior at School." Research in Autism Spectrum Disorders 4: 18-27. doi:10.1016/j.rasd,2009.07.002.

Australian Bureau of Statistics. 2012. Autism in Australia. cat. no. 4428.0.

Batten, A., and J. Daly. 2006. Make School Make Sense: Autism and Education in Scotland: The Reality for Families Today.

Bilken, D., and J. Burke. 2007. “Presuming Competence.” Equity \& Excellence in Education 39 (2): 166-175. doi:10. 1080/10665680500540376.

Coffey, K., and S. J. Obringer. 2004. "A Case Study on Autism: School Accommodations and Inclusive Settings." Education 124: 632-639.

Conn, C. 2014. "Investigating the Social Engagement of Children with Autism in Mainstream Schools for the Purpose of Identifying Learning Targets." Journal of Research in Special Educational Needs 14: 153-159. doi:10.1111/14713802.12010 .

Emam, M., and P. Farrell. 2009. "Tensions Experienced by Teachers and Their Views of Support for Pupils with Autism Spectrum Disorders in Mainstream Schools.” European Journal of Special Needs Education 24: 407-422. doi:10.1080/08856250903223070.

Gray, C., and J. Donnelly. 2013. "Unheard Voices: The View of Traveller and Non-traveller Mothers and Children with ASD.” International Journal of Early Years Education 21: 268-285. doi:10.1080/09669760.2013.842160.

Hay, I., and S. Winn. 2005. "Students with Asperger's Syndrome in an Inclusive Secondary School Environment: Teachers', Parents' and Students' Perspectives.” Australasian Journal of Special Education 29: 140-154.

Hebron, J., and N. Humphrey. 2014. "Mental Health Difficulties among Young People on the Autistic Spectrum in Mainstream Secondary Schools: A Comparative Study." Journal of Research in Special Educational Needs 14: 22-32. doi:10.1111/j.1471-3802.2012.01246.x.

Hedges, S., A. Kirby, M. Sreckovic, S. Kucharczyk, K. Hume, and S. Pace. 2014. “'Falling Through the Cracks': Challenges for High School Students with Autism Spectrum Disorder.” The High School Journal 98 (1): 64-82. doi: $10.1353 /$ hsj.2014.0014.

House of Commons Education and Skills Committee. 2006. Special Educational Needs. In (SEN) HC 478-1. London: The Stationery Office Limited.

Howley, M., and S. Kime. 2003. "Policies and Practice for the Management of Individual Learning Needs.” In Strategies to Promote Inclusive Practice, edited by C. Tilstone and R. Rose, 18-33. London: RoutledgeFalmer.

Howlin, P., S. Savage, P. Moss, A. Templer, and M. Rutter. 2014. “Cognitive and Language Skills in Adults with Autism: A 40-Year Follow-Up.” Journal of Child Psychology and Psychiatry 55: 49-58. doi:10.1111/jcpp.12115.

Humphrey, N., and S. Lewis. 2008. "Make Me Normal': The Views and Experiences of Pupils on the Autistic Spectrum in Mainstream Secondary Schools." Autism 12: 23-46. doi:10.1177/1362361307085267.

Humphrey, N., and W. Symes. 2011. "Peer Interaction Patterns among Adolescents with Autistic Spectrum Disorders (ASDs) in Mainstream School Settings.” Autism 15: 397-419. doi:10.1177/1362361310387804.

Humphrey, N., and W. Symes. 2013. "Inclusive Education for Pupils with Autistic Spectrum Disorders in Secondary Mainstream Schools: Teacher Attitudes, Experience and Knowledge.” International Journal of Inclusive Education 17: 32-46. doi:10.1080/13603116.2011.580462. 
Iadarola, S., S. Hetherington, C. Clinton, M. Dean, E. Raeisinger, L. Huynh, J. Locke, et al. 2015. "Services for Children with Autism Spectrum Disorder in Three, Large Urban School Districts: Perspectives of Parents and Educators." Autism 19: 694-703. doi:10.1177/1362361314548078.

Jackson Brewin, B., R. Renwick, and A. Schormans. 2008. "Parental Perspectives of the Quality of Life in School Environments for Children with Asperger Syndrome." Focus on Autism and Other Developmental Disabilities 23: 242-252. doi:10.1177/1088357608322997.

Johansson, S. 2014. “'He Is Intelligent but Different': Stakeholders' Perspectives on Children on the Autism Spectrum in Urban Indian School Context." International Journal of Disability, Development and Education 61: 416-433. doi:10.1080/1034912X.2014.955786.

Lindsay, S., M. Proulx, N. Thomson, and H. Scott. 2013. "Educators' Challenges of Including Children with Autism Spectrum Disorder in Mainstream Classrooms." International Journal of Disability, Development and Education 60: 347-362. doi:10.1080/1034912X.2013.846470.

Loiacono, V., and A. Palumbo. 2011. "Principals Who Understand Applied Behavior Analysis Perceive They Are Better Able to Support Educators Who Teach Students with Autism." International Journal of Special Education 26: $212-222$.

Lynch, S. L., and A. N. Irvine. 2009. "Inclusive Education and Best Practice for Children with Autism Spectrum Disorder: An Integrated Approach.” International Journal of Inclusive Education 13: 845-859. doi:10.1080/ 13603110802475518.

Matson, J. L., J. Wilkins, and J. Macken. 2008. “The Relationship of Challenging Behaviors to Severity and Symptoms of Autism Spectrum Disorders.” Journal of Mental Health Research in Intellectual Disabilities 2 (1): 29-44. doi:10. 1080/19315860802611415.

Mayton, M. 2004. “The Quality of Life of a Child with Asperger's Disorder in a General Education Setting: A Pilot Case Study.” International Journal of Special Education 20: 85-101.

McTiernan, A., G. Leader, O. Healy, and A. Mannion. 2011. "Analysis of Risk Factors and Early Predictors of Challenging Behavior for Children with Autism Spectrum Disorder." Research in Autism Spectrum Disorders 5: 1215-1222. doi:10.1016/j.rasd.2011.01.009.

Miles, M. B., and A. M. Huberman. 1994. Qualitative Data Analysis: An Expanded Sourcebook. 2nd ed. Thousand Oaks, CA: Sage.

Prizant, B. M. 2015. Uniquely Human: A Different Way of Seeing Autism. New York: Simon \& Schuster.

Ravet, J. 2011. "Inclusive/Exclusive? Contradictory Perspectives on Autism and Inclusion: The Case for an Integrative Position.” International Journal of Special Education 15: 667-682. doi:10.1080/13603110903294347.

Saggers, B., Y.-S. Hwang, and L. Mercer. 2011. "Your Voice Counts: Listening to the Voice of High School Students with Autism Spectrum Disorders.” Australasian Journal of Special Education 35 (2): 173-190. doi:10.1375/ajse.35.2.173.

Sansosti, J., and F. Sansosti. 2012. "Inclusion for Students with High-Functioning Autism Spectrum Disorders: Definitions and Decision Making." Psychology in the Schools 49: 917-931. doi:10.1002/pits.21652.

Sciutto, M., S. Richwine, J.Mentrikoski, and K. Niedzwiecki. 2012. "A Qualitative Analysis of the School Experiences of Students with Asperger Syndrome." Focus on Autism and Other Developmental Disabilities 27: 177-188. doi:10. $1177 / 1088357612450511$.

Segall, M., and J. Campbell. 2012. "Factors Relating to Education Professionals' Classroom Practices for the Inclusion of Students with Autism Spectrum Disorders." Research in Autism Spectrum Disorders 6: 1156-1167. doi:10.1016/j. rasd.2012.02.007.

Snyder, T. D., and S. A. Dillow. 2013. Digest of Education Statistics (NCES 2014-015). National Center for Education Statistics, Institute of Education Sciences.

Soto-Chodiman, R., J. Pooley, and M. Taylor. 2012. "Students with ASD in Mainstream Primary Education Settings: Teachers' Experiences in Western Australian Classrooms.” Australasian Journal of Special Education 36: 97-111. doi:10.1017/jse.2012.10.

United Nations Educational Scientific and Cultural Organisation. 1994. Salamanca Statement and Framework for Action on Special Needs.

Waddington, E., and P. Reed. 2006. "Parents' and Local Education Authority Officers' Perceptions of the Factors Affecting the Success of Inclusion of Pupils with Autistic Spectrum Disorders." International Journal of Special Education 21: 138-150.

Whitaker, P. 2007. "Provision for Youngsters with Autistic Spectrum Disorders in Mainstream Schools: What Parents Say - and What Parents Want." British Journal of Special Education 34: 170-178.

Wolff, S. 2004. “The History of Autism.” European Child \& Adolescent Psychiatry 13: 201-220. doi:10.1007/s00787004-0363-5.

Yumak, N., and E. Akgul. 2010. “Investigating Elementary School Administrators' and Teachers' Perceptions on Children with Autism." Procedia - Social and Behavioral Sciences 2: 910-914. doi:10.1016/j.sbspro.2010.03.125. 